\title{
Single-crystal neutron diffraction study of ferroelectric $\mathrm{Ba}_{0.92} \mathrm{Ca}_{0.08} \mathrm{TiO}_{3}$
}

\author{
H RAJAGOPAL, P U M SASTRY, A SEQUEIRA and P RAMASAMY* \\ Solid State Physics Division, Bhabha Atomic Research Centre, Trombay, Bombay 400085, \\ India \\ *Crystal Growth Centre, Anna University, Madras 600025, India \\ MS received 16 November 1993; revised 14 February 1994
}

\begin{abstract}
Crystal structure of $\mathrm{BaTiO}_{3}$ doped with $8 \% \mathrm{Ca}^{2+}$ is refined using single-crystal neutron diffraction data and it is shown that the doped $\mathrm{Ca}^{2+}$ ion substitutes only at the Ba sites. The refined cell $(\mathrm{P} 4 \mathrm{~mm})$ parameters are $a=b=3.982(3) \AA, c=4.003(3) \AA$ with a final $R$ value of 0.02 (on $F$ ). Existence of multiple domains in the crystal is ruled out based on refinement with multidomain model.
\end{abstract}

Keywords. Neutron diffraction; ferroelectric $(\mathrm{Ba} / \mathrm{Ca}) \mathrm{TiO}_{3}$.

\section{Introduction}

The nature of ferroelectric transition in $\mathrm{BaTiO}_{3}$ is reported to be sensitive to doping with $\mathrm{Ca}^{2+}$ ion (Zhuang et al 1987; Tiwari et al 1991). According to Zhuang et al, a small amount $(<3 \%)$ of $\mathrm{Ca}^{2+}$ at $\mathrm{Ti}^{4+}$-sites leads to diffusive nature of transitions and significantly lowers the transition temperature $\left(T_{c}\right)$ compared to pure $\mathrm{BaTiO}_{3}$. On the contrary, Tiwari et al (1991) observed from their powder diffraction and dielectric measurements that it is the occupancy of $\mathrm{Ba}$ sites by $\mathrm{Ca}$ ions which is responsible for the diffusive transition and depending upon the method of preparation $\mathrm{Ca}$ ion can enter either $\mathrm{Ba}$ site or Ti site. Unpublished dielectric measurements by D Pandey on single crystals of $\mathrm{Ba}_{1-x} \mathrm{Ca}_{x} \mathrm{TiO}_{3}$ grown by flux method have confirmed that these crystals $(x=0.1$ and $x=0.2)$ show a broad hump in dielectric constant at a temperature near the tetragonal to cubic transition of pure $\mathrm{BaTiO}_{3}$. In order to throw more light on the site of occupancy of $\mathrm{Ca}^{2+}$ and its role on the ferroelectric behaviour of the material, a neutron structural study has been carried out on a single crystal of $\mathrm{Ba}_{0.92} \mathrm{Ca}_{0.08} \mathrm{TiO}_{3}$ grown by flux method.

\section{Experimental}

$\mathrm{Ba}_{0.92} \mathrm{Ca}_{0.08} \mathrm{TiO}_{3}$ crystals were grown by Remeika's (1954) technique using $\mathrm{KF}$ as flux. A mixture containing $30 \%\left(\mathrm{BaCO}_{3}+\mathrm{CaCO}_{3}+\mathrm{TiO}_{2}\right)$ and $70 \% \mathrm{KF}$ was taken in a platinum crucible and heated to $1200^{\circ} \mathrm{C}$. After a certain soaking time the temperature was lowered to $850^{\circ} \mathrm{C}$. At this temperature, the flux was decanted and the crystals were cooled to room temperature. The grown crystals were recovered using hot distilled water. By performing the growth run with a slow cooling rate of $3^{\circ} \mathrm{C} / \mathrm{h}$ and a soaking period of $15 \mathrm{~h}$, high-quality crystals with enhanced size of about $5 \times 5 \times 15 \mathrm{~mm}^{3}$ were obtained.

The crystal used for recording neutron diffraction data was in the shape of a rectangular parallelepiped $\left(3.3 \times 2.4 \times 1.9 \mathrm{~mm}^{3}\right)$, with the longest side parallel to the 
Table 1. Refined structural parameters of $8 \% \mathrm{Ca}$-doped $\mathrm{BaTiO}_{3}(B$ is isotropic temperature factor and $N$ is site occupancy).

\begin{tabular}{|c|c|c|c|c|c|}
\hline \multicolumn{6}{|c|}{$\begin{array}{l}\text { Space group }=\mathrm{P} 4 \mathrm{~mm} \\
\text { Cell parameters: } a=b=3.982(3) \AA, c=4.008(3) \AA \\
\text { Cell volume }(V)=63.552 \AA^{3}\end{array}$} \\
\hline Atom & $x$ & $y$ & $z$ & $B \AA^{2}$ & $N$ \\
\hline $\mathrm{Ba}$ & 0 & 0 & 0 & $0 \cdot 38(10)$ & $0.905(6)$ \\
\hline $\mathrm{Ca}$ & 0 & 0 & 0 & $0 \cdot 38(10)$ & 0.079 \\
\hline $\mathrm{Ti}$ & 0.5 & 0.5 & $0 \cdot 509(1)$ & $0 \cdot 21(8)$ & $1 \cdot 0$ \\
\hline$O(1)$ & 0.5 & 0.5 & $-0.0206(9)$ & $0.53(10)$ & $0.992(5)$ \\
\hline$O(2)$ & 0.0 & 0.5 & $0.487(1)$ & $0.63(9)$ & $2 \cdot 0$ \\
\hline
\end{tabular}

Extinction parameters (in units of $10^{14} \mathrm{~mm}^{-2}$ )

$W_{11}=0.596 \quad W_{12}=-0.298$

$W_{22}=0.306 \quad W_{13}=-0.058$

$W_{33}=0.232 \quad W_{23}=0.022$

$b$-axis and the shortest side parallel to the $c$-axis. This crystal was mounted with its $b$-axis along the $\phi$-axis of the on-line computer-controlled four-circle neutron diffractometer (Rajagopal et al, to be published) at Dhruva reactor, Trombay. The cell parameters and crystal orientation were refined using optimized $2 \theta, \chi$ and $\phi$ values for 25 strong reflections using the program.REFINE (S Srikanta and A Sequeira 1968, unpublished). The refined values of cell constants are listed in table 1 along with other data. Integrated intensities of 88 reflections covering half the reciprocal sphere within the limit of $\sin (\theta) / \lambda=0.5 \AA^{-1}(\lambda=1.216 \AA)$ were recorded using $\theta-2 \theta$ coupled step scanning technique. The scan length was varied to include at least 10 background steps on either side of the peak. Two standard reflections (200) and (002) were measured at regular intervals to monitor the stability of the crystal and the reproducibility of measurements. Intensity fluctuation in these reflections were within $2 \%$ from the mean values during the entire experiment. The space group extinctions for P4 $\mathrm{mm}$ were confirmed. The integrated intensities were reduced to $F^{2}$ by applying the standard Lorentz and absorption corrections using the program DATARED (H Rajagopal, S Srikanta and A Sequeira 1973, unpublished), which includes the absorption correction program ORABS (Wehe et al 1962) as a subroutine. An absorption coefficient of $0.0114 \mathrm{~mm}^{-1}$ was used. The transmission coefficients ranged between 0.976 and 0.98 .

\section{Refinement}

The initial model involving variable $z$-parameters for $\mathrm{Ti}, \mathrm{O}(1)$ and $\mathrm{O}(2)$ atoms and isotropic temperature factors $(B)$ for all the atoms along with the scale factor and an isotropic extinction factor were refined using the program TRXFLS (H Rajagopal and A Sequeira 1977, unpublished), a modified version of ORFLS (Busing et al 1962). The quantity minimized was the function $\Sigma w\left(F_{o}^{2}-F_{c}^{2}\right)^{2}$ with initial weights

$$
w=\left\{\sigma_{\mathrm{ST}}\left(F_{o}^{2}\right)+\left(0.03 * F_{o}^{2}\right)^{2}\right\}^{-1},
$$


where $\sigma_{\mathrm{ST}}\left(F_{o}^{2}\right)$ were the standard errors based on counting statistics. The neutron scattering lengths used were $5 \cdot 25,4 \cdot 9,-3.44$ and $5.8 \mathrm{fm}$ for $\mathrm{Ba}, \mathrm{Ca}$, Ti and $\mathrm{O}$ atoms respectively. Further refinements were carried out by floating cation-site occupancies and fixing full occupancies for oxygen sites. The refinements indicated that the Ti sites were fully occupied by $\mathrm{Ti}$ ions and $\mathrm{Ba}$ sites are occupied by $\mathrm{Ba}$ ions as well as the $\mathrm{Ca}$ ions. The occupancies of $\mathrm{Ca}$ and $\mathrm{Ba}$ at the $\mathrm{Ba}$ sites were refined with the constraint $N(\mathrm{Ca}) / N(\mathrm{Ba})=8 / 92$. Subsequently, refinements of oxygen-site occupancies carried out individually indicated full occupancy at $O(2)$ sites and nearly full $(99 \cdot 2 \%)$ occupancy at $\mathrm{O}(1)$ sites. Finally, a further set of refinements were also carried out using anisotropic type-I as well as type-II extinctions. Significant improvement in the $R$-factor was obtained only when the type-II extinction was used. (Structure factor table has been deposited with the journal.) The extinction parameters are listed along with the refined structural and thermal parameters in table 1.

In order to rule out the possibility of existence of multiple domains in this crystal, refinements were also carried out with multidomain model by suitable modification of the least-squares program TRXFLS. In this model, the contribution from three possible types of twin domains, viz. XYZ, YZX and ZXY, related by three-fold axis of the prototype cubic symmetry, were included. Both the single and multidomain models yielded comparable $R$ (on $F$ ) values of 0.02 and 0.0198 respectively. The choice of multidomain model involving two additional parameters could be ruled out at a significant level of better than 0.005 based on Hamilton's significance test (Hamilton 1965). This is also consistent with the fact that the observed diffraction peak widths were not increased compared to those expected for a single-domain crystal.

\section{Results and discussion}

The refinement indicates that $\mathrm{Ca}$ ions occupy $\mathrm{Ba}$ sites although the presence of a small amount of vacancies $(<1.5 \%)$ at the $\mathrm{Ba}$ sites cannot be ruled out. The apical $O(1)$ sites also indicate nearly $1 \%$ vacancies. However existence of such vacancies in ferroelectric materials is not ruled out (Kulagin 1989). Bond distances are listed in table 2, and are compared with the values for undoped $\mathrm{BaTiO}_{3}$ determined by neutron diffraction (Harada et al 1970). Unit cell volume and the $c / a$ ratio of pure, $5 \%-\mathrm{Ca}-$ doped powder $\mathrm{BaTiO}_{3}$ samples (Zhuang et al 1987), and our ( $8 \%$-doped) single crystal are compared in table 3 . From table 3 it is suggested that as more $\mathrm{Ca}$ enters $\mathrm{Ba}$ site, the structure approaches cubic symmetry. Combining our result with that of $D$ Pandey (that the dielectric constant exhibits a broad hump, as mentioned earlier) it can be inferred that the diffusive nature of ferroelectric behaviour in these crystals is

Table 2. Bond distances (in $\AA$ units) of pure and $8 \%$-Ca-doped $\mathrm{BaTiO}_{3}$ from neutron diffraction.

\begin{tabular}{llc} 
& Pure BaTiO & $\mathrm{Ba}_{0.92} \mathrm{Ca}_{0.08} \mathrm{TiO}_{3}$ \\
\hline $\mathrm{Ti}-\mathrm{O}(1)$ & $2 \cdot 172(1)$ & $2 \cdot 121(9)$ \\
$\mathrm{Ti}-\mathrm{O}(2)$ & $2 \cdot 03(2)$ & $1.993(2)$ \\
$\mathrm{Ba}-\mathrm{O}(1)$ & $2 \cdot 8425(1)$ & $2 \cdot 817(2)$ \\
$\mathrm{Ba}-\mathrm{O}(2)$ & $2 \cdot 7948(1)$ & $2 \cdot 790(4)$ \\
\hline
\end{tabular}


Table 3. Unit cell properties of pure, 5\%-Ca-doped, and $8 \%$-Ca-doped $\mathrm{BaTiO}_{3}$.

\begin{tabular}{lccccc}
\hline Compound & $a(\AA)$ & $b(\AA)$ & $c(\AA)$ & $c / a$ & Volume $\left(\AA^{3}\right)$ \\
\hline $\mathrm{BaTiO}_{3}$ & $3.996(1)$ & $3.996(1)$ & $4.040(1)$ & 1.0109 & 64.524 \\
$\mathrm{Ba}_{0.95} \mathrm{Ca}_{0.05} \mathrm{TiO}_{3}$ & $3.990(1)$ & $3.990(1)$ & $4.036(1)$ & 1.0113 & 64.26 \\
$\mathrm{Ba}_{0.92} \mathrm{Ca}_{0.08} \mathrm{TiO}_{3}$ & $3.982(3)$ & $3.982(3)$ & $4.008(4)$ & 1.0065 & 63.552 \\
\hline
\end{tabular}

essentially due to the occupancy of $\mathrm{Ca}$ ion at Ba site. According to Zhuang et al (1987) the Curie peak of dielectric constant broadens over a range of temperature due to internal stress distribution across the lattice caused by the $\mathrm{Ca}$-ion substitution at the Ti site. Probably the observed diffusive nature of ferroelectric transition in our crystal is also due to nonuniform distortion of the lattice due to $\mathrm{Ca}$ ion substitution at $\mathrm{Ba}$ site. The effect of $\mathrm{Ca}$ ion substitution on the lattice is indicated by the volume change (see table 3). As expected, the cell volume decreases as more and more smaller $\mathrm{Ca}$ ion replaces the larger $\mathrm{Ba}$ ion. Detailed analysis of the nature of distortion of $\mathrm{BaTiO}_{3}$ lattice and its correlation to the observed diffusive ferroelectric behaviour is currently in progress.

\section{Conclusion}

From our structure analysis it can be concluded that if a crystal of $\mathrm{BaTiO}_{3}$ doped with $8 \% \mathrm{Ca}^{2+}$ is prepared by flux method, $\mathrm{Ca}^{2+}$ ion exclusively enters $\mathrm{Ba}$ site and leads to diffuse phase transition. As more and more $\mathrm{Ca}$ enters $\mathrm{Ba}$ site the structure approaches cubic symmetry.

\section{References}

Busing W R, Martin K O and Levy H A 1962 ORFLS report ORNL-TM-305, Oak Ridge National Laboratory, Oak Ridge, Tennessee, USA

Hamilton W C 1965 Acta Crystallogr. 18502

Harada J, Pedersen T and Barnea Z 1970 Acta Crystallogr. A26 336

Kulagin N 1989 Ferroelectrics 92319

Remeika J P 1954 J. Am. Ceram. Soc. 76940

Tiwari V S, Pandey D, Krishna P S R, Chakravarthy R and Dasannacharya B A 1991 Physica B174112

Wehe D J, Busing W R and Levy H A 1962 ORABS report TM-229, Oak Ridge National Laboratory, Oak Ridge, Tennessee, USA

Zhuang Z Q, Harmer M P, Smnyth D M and Nèwnham R E 1987 Mater. Res. Bull. 221329 